\title{
The authorising roles of public institutions in job creation and training: legitimating New Zealand employment policy 1980 - 1985
}

\author{
Martin O'Connor*
}

This paper analyses the roles of central and local government public sector institutions in conferring and denying ideological legitimacy to alternative job creation and training strategies. The past decade has seen numerous changes in employment policy direction. In all cases the policy changes have been accompanied by the promulgation of rhetorical information proclaiming why and how they represent rational and appropriate responses to identified problems. There has in fact been no general consensus on priorities nor on the best means to achieve objectives. Institutional power to authorise particular policy rationales therefore is of paramount importance in determining what forms support for employment initiatives are able to take. Through a review of the past decade of the public sector special employment programmes, this paper traces and interprets the dynamics of this coercive political process, and its part in wider social change in New Zealand.

\section{Introduction}

Recent employment policy has been one of the more controversial issues facing New Zealand decisionmakers and the "public" to whom they are responsible. Since the rapid increase in numbers of registered unemployed in the latter 1970 s, the country has seen numerous major and minor changes in general policy direction. In the content of the public sector special job creation and training programmes in particular, three major transition periods can be identified: (1) from TES to PEP around 1980; (2) the re-vamping of all programmes with an up-grading of the "training" orientation during 1982; (3) the reconstruction being effected by the current Labour administration, during 1985 and beyond.

These changes have occurred in large part in response to pressures on central government and other public institutions by vociferous interest groups, e.g. the unemployed New Zealanders themselves, employer and trade union groups, Maori and community interests, local authorities. But the changes have not necessarily reflected the views and priorities of these partisan interests. The shape of policy initiatives has been also a function of (inter alia) central government decisionmakers concerns (1) to regulate and to retain centralised accountability for the substantial expenditures in the area of employment subsidies, and (2) to develop some elements of sensible and coherent purpose regarding the existing or proposed programmes. In all cases the policy changes have been accompanied with a rhetorical discourse on why and how they represent a rational and appropriate response to the identified problems. Such "explanatory" information deriving from "official" sources invariably has proposed that "responsible" New Zealanders will discern this rationality and support the policy. Yet the implemented changes have equally invariably been adjudged as disappoint-

* Lecturer, Department of Economics, University of Auckland.

\footnotetext{
The research upon which this article depends was undertaken with assistance in many forms from numerous individuals and institutions, including in particular the Employment Network, the Auckland City Council, and the Department of Labour. Thanks to all those who have collaborated in past research projects (with and without monetary reward) and in the production of this manuscript. The author is grateful also for extensive comments on an earlier draft provided by Tony Endres. Dennis Rose, and 2 anonymous referees, which have helped greatly in clarifying the presentation and remedying defects in the argument. Responsibility for any remaining errors, and for the interpretive content of this paper remains solely with the author.
} 
ing, and criticised by many interested parties as failing to address some (or all) of the "real issues". There has indeed been no general consensus on priorities, nor on the best means to achieve objectives.

In this policy climate, institutional power to authorise particular policy choices becomes of paramount importance in determining what forms support for employment initiatives will take. Access to resources, and the "right" to employ centrally administered resources in pursuit of variously conceived social, cultural, and economic development objectives, is regimented to fit (at least on the face of things) the prevailing policy wisdom. To say this is, obviously, to admit the fact of coercion and of conflict within our society, and the differential abilities of different types of interest groups and individuals to realise favoured social/economic development objectives.

This paper analyses some aspects of the immensely influential roles of public sector institutions in conferring, and denying, ideological legitimacy to alternative job creation and training strategies. Illustrative material is drawn primarily from major institutional documents which have been published or become publicly available during the period 1980-1985. The intention is to report on the general drift of policy formation and execution in New Zealand as a political process during these years, specifically to draw attention to the related issues of authority, power and information in the employment policy debate.

\section{Methodological perspective}

Recent studies of New Zealanders' attitudes on work and employment issues show a wide diversity of conservative and change-oriented views and differences with similar basic development values. For example an analysis by Averton et al. (1985) observes a widespread consensus amongst New Zealanders that unemployment is a serious problem. For most, its critical character derives from the perception that it excludes people from "full participation" as a member of our social system:

In many people's view, work is a right for all who want it. It is also widely regarded as a duty, being part of the usual way in which people make a contribution in society. Paid employment is therefore central to people's standards of living both in the usual material sense, and also in the sense of being a fundamental social value or norm by which people measure their participation in society (Averton et al. 1985, p 6)

As regards favoured responses to unemployment-related problems, however, there is little consensus. "Perhaps the only point of universal agreement is that there are mis-matches between the opportunities provided by the system at present, and people 's employment needs" (ibid). Perceptions of the appropriate directions for attempting economic recovery and/or social changes to overcome the problem range over a wide spectrum:

Underpinning the traditional (Pakeha) values concerning employment in our society is the presumption that economic growth provides the basis for the satisfaction of the needs of all members of society ..... A widespread judgement in response to this perception is that the solving of employment problems is also to be considered in terms of the future provision of paid employment and a satisfactory \$-standard of living. This view seems to dominate in most employer, union, and government sources. But ...... there are further people who feel that even if in purely economic terms there might be sufficient growth to offer opportunities of work for all, the sorts of work available are unlikely to be satisfying or meaningful in terms of their personal and cultural valued. (ibid. p 18)

Even within the more conventional wisdoms, oriented towards solutions via market-led or/and government-guided GNP growth, there are abundant differences of view as to the appropriateness of different policy options and their likely effectiveness. The pluralism amongst professional economists as to which model(s) of the economy offer(s), for purposes

1. There is a relatively low level of professional research on socio-economic aspects of employment in New Zealand. Much of the research that has been done is fragmented, unpublished, and poorly disseminated. This, in part, reflects a reluctance, until recently, of government agencies to fund large-scale research work into admittedly sensitive issues. Some studies of an occasional nature have been undertaken by such institutions as the New Zealand Planning Council and New Zealand Institute for Economic Research, focussing mostly on "economic" aspects. Among others of a more "social" character are: Abbott: (1982); Averton et al. (1985); Cooney \& O'Connor (1983): Cronin (1983); EPC (1985a, 1985b); Hutchinson (1984a, 1984b); Kerslake (1984): O'Connor \& Brown (1983): Rodin (1983); Duff (1984). 
of policy analysis, the most useful representation(s), and as to the desirable roles of government in regulatory and distributional objectives, is a case in point.

Incompleteness of the available information on social and economic aspects of the current labour market and unemployment situation (see footnote 1) is only a part of the basis for these divergent perceptions. More fundamental are the ambiguities as to the interpretation of the current situation, due to the complexity of economic change processes; the inevitable mutual informing of fundamental personal and cultural values and theoretical apparatuses; and available data in the context of formal or informal models of economic processes. There are many models of reality, as well as visions of a possible or desirable future, which may coexist receiving some corroboration from whatever aspects of the labour market/unemployment situation any given institution or individual preoccupies itself with. Employment creation programmes have been formulated and re-formulated repeatedly, in this climate of contradictory perceptions and interests, change, tension, and uncertainty. The immediate aim of this paper is to examine critically the persuasive role of central government in influencing which visions of the future, and which models of the present, come to inform implemented policy, and the implications for those people whose views do not prevail.

The processes of consultation and submission, policy analyses and initiatives, and the bureaucratic administrative structures, are components in an ongoing process of social transformation which leaves none of the participants untouched or unchanged. Institutions such as central and local government departments, and individuals within them, are by law and convention vested with authority to execute and regulate different social activities. These authorities institute structures of meaning in our society which codify social action and relationships, in part through the construction, circulation, and control of information in society. Information is not neutral; rather it is expressed in and through inter-action by which people inform themselves, and seek to inform others. Significant differences and conflicts exist between different social groups over the perception of the nature, causes, and appropriate responses to un/employment problems. Groups and individuals who find themselves at odds with institutionally legitimated forms of action, must express their opposition dialectically in relation to the status quo. The power structures in society strongly affect which views receive widespread currency and are most reflected in decision making at various levels, and which views circulate, if at all, only as marginal discourses henceforth labelled radical, deviant, extreme, or way out (etc) by reference to the dominant views. Groups or individuals who express such dissidence are often perceived as a threat to the stability (reproduction) of the social system.

In practice, information tending to the reproduction of traditionally dominant social institutions and norms concerning un/employment, circulates through New Zealand society alongside information and action challenging status quo structures and seeking change at more or less radical levels. Information in our society is a tool of action, creation, and persuasion. Interest groups construct and circulate information, in effect seeking to institute particular views within society, and to encourage other parties to identify with roles consistent with these desired forms. Far from providing neutral and "objective" tools for policy evaluation, economic models and techniques of analysis represent particular ways of viewing social processes. Their employment, in whatever variations by authoritative social institutions, tends to privilege policy initiatives which are conceptually compatible with the theory, in some cases legitimating what others in our society perceive as historical patterns of disadvantage and cultural bias. The tensions between contrary views, whether these are at the level of underlying cultural values, disagreements over economic equity objectives, or models informing different evaluations of the desirability and effectiveness of a policy option to achieve an agreed distributional end, are indeed important factors influencing the directions of change in our society. It would seem desirable that policy development, evaluation and review processes be developed that accept this pluralism in its creative aspects.

One can in this context make use of the systems analysis of a dialectical complementarity between existing structure and change to a system. On the one hand are processes of communication (i.e. of information action and social relationships) geared towards the reproduction of existing dominant (i.e. already instituted) social structures and ideologies; on the other hand, views and visions which question the existing structures and values, seeking more or less fundamental changes. This is diagramatically represented in Figure 1.

To propose this dialectical opposition is admittedly a simplification, a way of representing some aspects of the political processes associated with employment policy in New Zealand. The intent of this theoretical construction of things is to draw attention to the complex interplays of different views and visions of development in the employment policy arena. 
Figure 1: Social dynamics of information engendering reproduction of and change to instituted norms of behaviour: schematic representation.

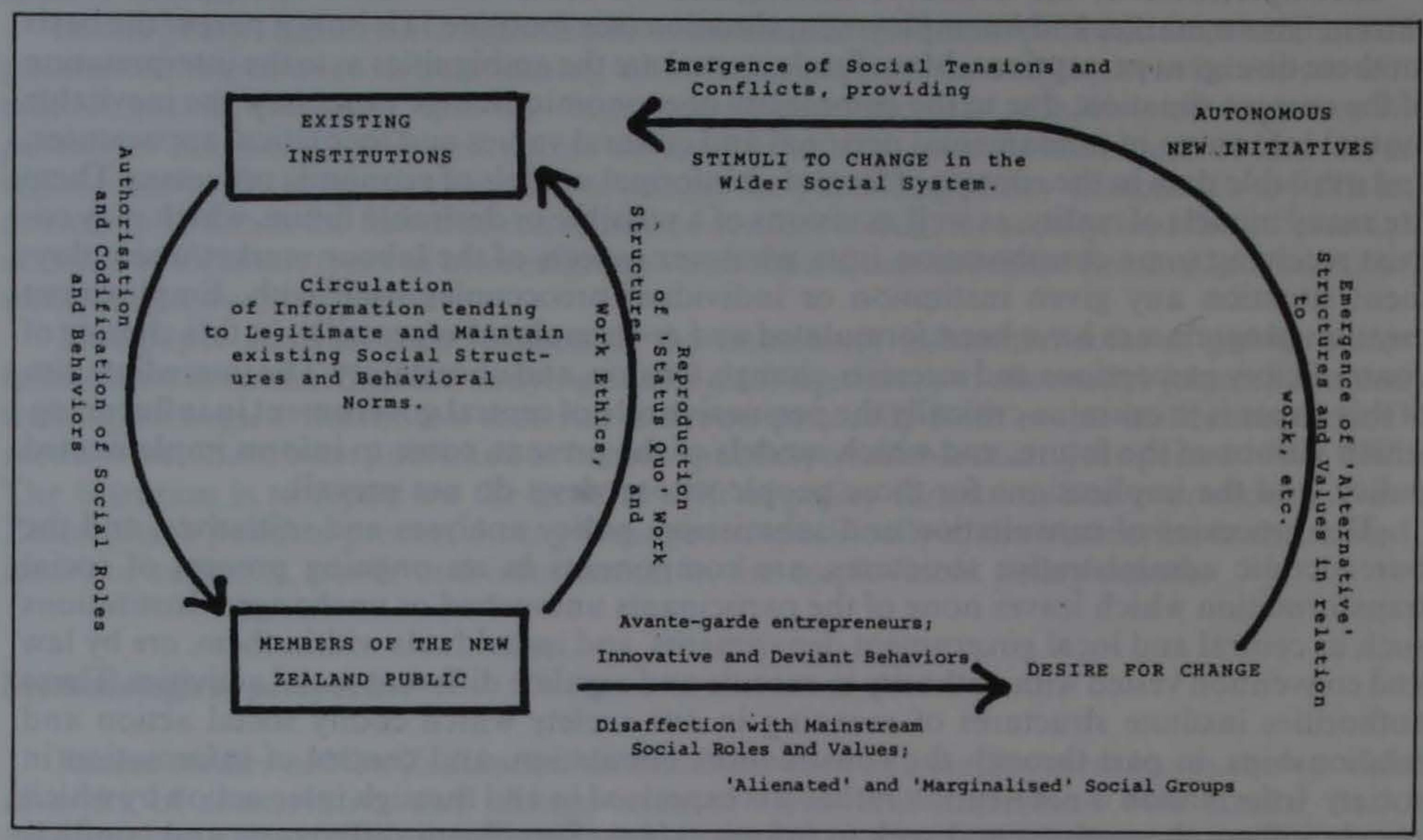

As such, this paper presents one view among many others, on the process of employment policy formation and transformation. It is an interpretive analysis grounded in participation within the social processes on which I am writing. Theoretically sophisticated practice may add discipline and (one hopes) precision in the process of analysing and informing individual and collective economic action and its projected outcomes. But all economic and political science remains grounded in and motivated by normative interests, and this paper makes no claim to have escaped "outside" all value judgements. If the present argument is partisan, it is not so much in favour of any particular model of social processes, but in favour of a metamodel which acknowledges as legitimate the articulation of sometimes incommensurate and conflicting views and values, and in favour of policies which give genuine recognition to this diversity of human interests. The cogency of this partiality relies on what will be the central thesis of this paper: that such pluralism has yet to be manifest in New Zealand employment policy.

\section{From TES to PEP: the "bridge" to full employment}

Most important amongst the special employment programmes during the latter 1970s were the Temporary Employment Scheme (TES) and related public sector measures. These had their origins in Special Work regulations put into place in times of economic stress since the mid-1960s (Forer 1980). As economic conditions deteriorated after 1975, they were restyled and augmented to respond to growing unemployment numbers. During 1978-79, some 40-50 percent of those registered unemployed were provided with some employment support under the TES, with perhaps another 10 percent being placed through subsidised private sector schemes (Forer 1979; 1980). For example Department of Labour figures for 31 March 1979 , show some 23700 people registered unemployed, compared with 26100 then currently placed on job creation schemes, the great majority on TES. From 1978 until early 1980, TES was acting as a major employment support for a large proportion of people who became registered unemployed during this time.

As Figure 2 illustrates, generous use of TES during the late 1970s had thus continued to foster a widespread expectation that a person who became unemployed could reasonably hope to get "special" employment support through a temporary job. Liberal use of the programme by local authorities and government departments legitimated this role, and further, institutionalised TES as a means of improving or maintaining services without 
Figure 2: The end of "full employment" circa 1979

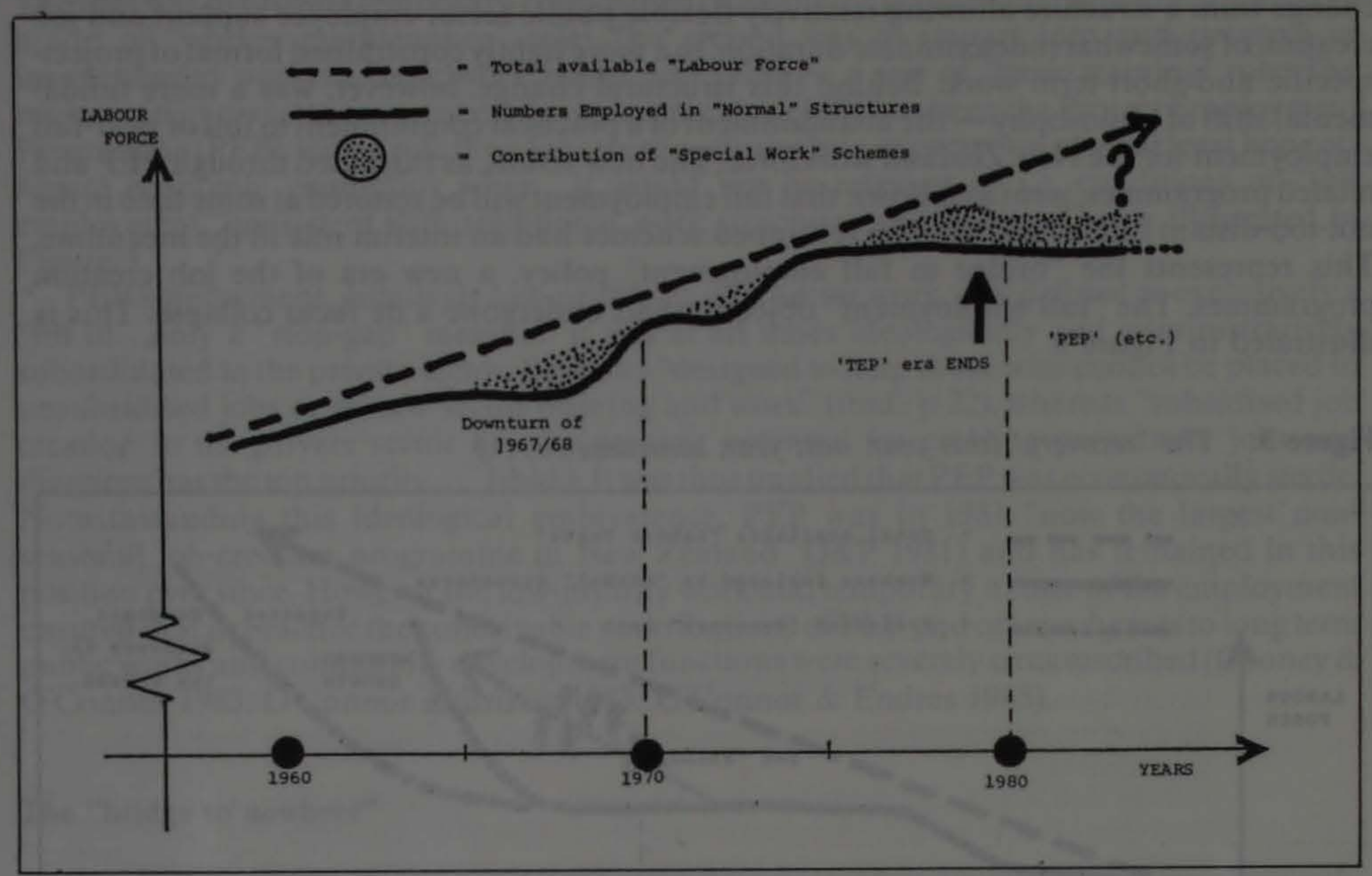

increasing rates or exceeding staff ceilings. TES in effect functioned to mask from the general public view the continuing rise in the numbers of persons lacking security of employment or work opportunity within traditional private and public sector forms. This allowed de facto preservation of the traditional New Zealand social commitment to the ideal of full employment as "a fundamental national value, and integral part of a belief cherished in New Zealand ..... that everyone gets a fair go" (Dwyer 1983; see also Endres 1984).

However the political and economic costs of the TES "cloak" were becoming very substantial. The drain on Treasury coffers in support of supposedly "low priority" public sector work, the semi-permanent character of many of the employment projects under TES, the repercussions of the 1979 "second oil shock", and the uncertain prospects of an improved growth and balance of payments position, became sources of major policy concern. The PSA and other labour interests expressed concern at the way the extensive use of TES was undermining security of employment opportunities and work conditions in the public sector. The gap revealed in the statistics, between numbers employed and numbers wishing to "participate in the workforce", can be correlated with a vacuum in policymakers', and the "New Zealand public's" grounds for action. A paucity of mechanisms for research and monitoring of labour market issues contributed to the absence of good information and analytic bases for policy evaluation. and hence in general a lack of clear resolution of an appropriate strategy or response in the absence of full employment. The prospect of the 1981 general election added, for many important social groupings, increased political urgency to the question.

To stem the flow of resources into temporary job creation, it would be necessary to radically reconstitute the rationale for subsidised employment schemes. In the absence of short-term growth prospects, this implied abandonment of the social ideal of full employment, at least in the "short-term". 1980 thus saw a major transformation to public sector programmes. These changes resulted in an assortment of more narrowly focussed programmes replacing the global TES structure. Leaving aside the student vacation work scheme (SCSP, introduced some years before), the most important public sector programmes in terms of numbers employed have subsequently been (1) the Project Employment Programme (PEP), which incorporated the Voluntary Organisation Job Creation programme (VOJCP); and (2) the Work Skills Development Programme (WSDP); along with several further schemes of lesser statistical importance. 
The most widely noted change during the time of the transition of TES to PEP was the change from a structure allowing relatively flexible public sector employee support and job creation of somewhat indeterminate duration, to a more tightly constrained format of projectspecific and short-term work. Behind this structural change, however, was a more fundamental shift of philosophy - the abandonment of a practical commitment to full or near-full employment for the New Zealand workforce. The new vision, as instituted through PEP and related programmes, went as follows: that full employment will be restored at some time in the not-too-distant future, and that the revamped schemes had an interim role in the meantime. This represents the "bridge to full employment" policy, a new era of the job creation programmes. The "full employment" objective had undergone a de facto collapse. This is illustrated in Figure 3.

Figure 3: The "recovery" (this year, next year, sometime.....)

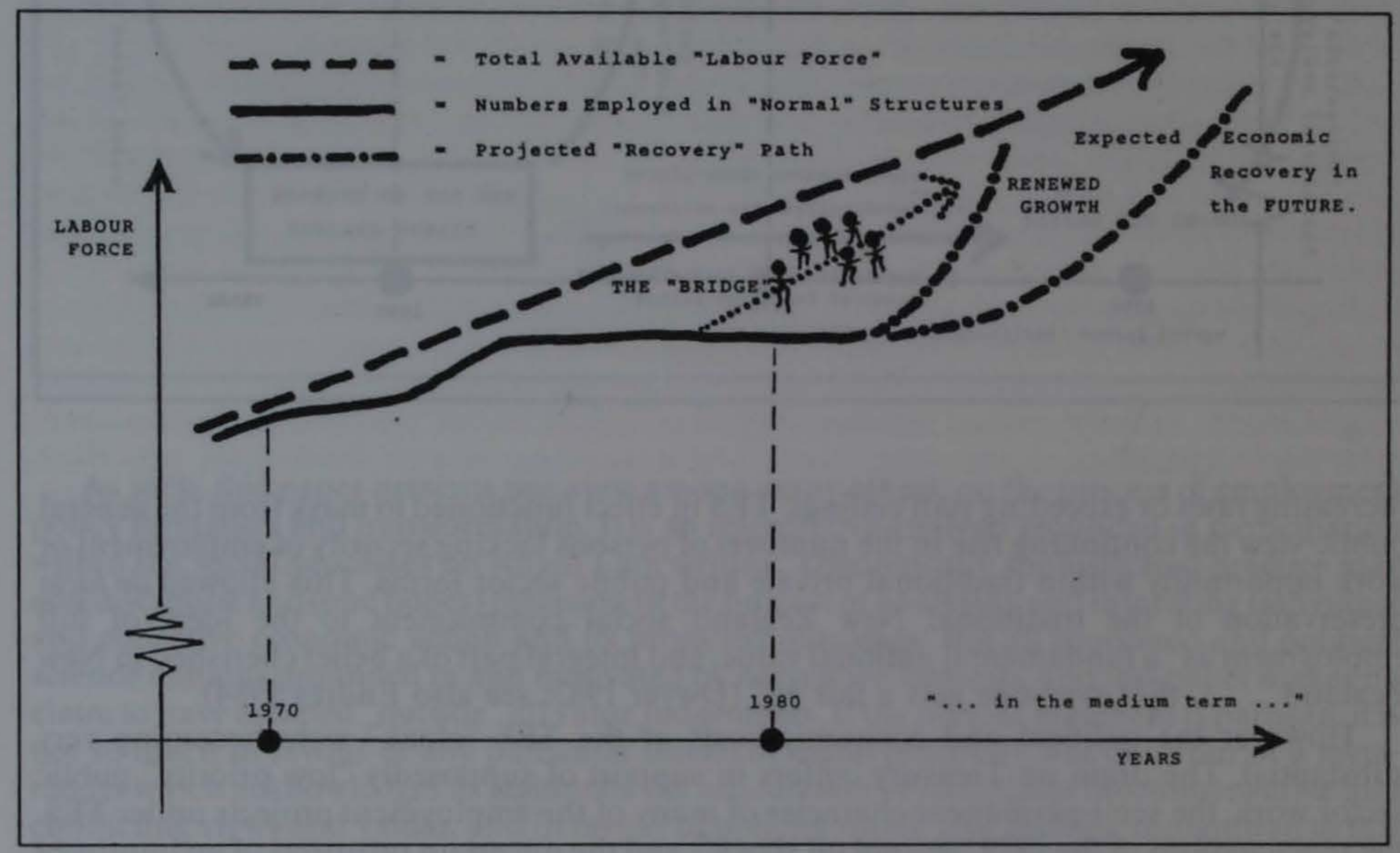

This was the revised version of "economic reality" promulgated to the New Zealand public in June 1981 by a Government public relations document, Jobs \& people: the Government's employment strategy (henceforth J\&P 1981), and instituted through the agency of the Departmental of Labour and other bureaucracies which administered the schemes. While it was recognised that some social groups were statistically more "at risk" than others, the primary focus remained in terms of aggregate levels.

Employment growth is fuelled by economic growth. The more goods and services are produced, the more job opporturities there are available. If the economy had been able to grow sufficiently, we would not have unemployment..... To support a greater number of jobs, a higher level of overseas earnings is essential...... The Government's economic strategy is aimed at restoring economic growth and, in doing so, creating the jobs required..

(J\&P 1981, p 8)

And by corollary,

At present however, there is a need to provide short-term support and subsidised job opportunities for those unable to find regular employment. Currently there are three private sector programmes and five in the public sector. All these are designed as far as possible as "bridges" to help people into unsubsidised employment. The Government is generally not prepared to provide indefinite wage subsidies for jobs, but these programmes cushion the impact of unemployment and open the way to real job opportunities. (J\&P 1981, p 22)

Thus, "some schemes provide immediate assistance to the people affected by job shortages. Others are designed to help people take advantage of the opportunities which will be created when economic growth is restored" (ibid.. p 27). 
Within this framework there were 2 broad functions intended of the public sector schemes. The first was to provide temporary employment support for people otherwise unemployed a sort of "worker maintenance" role. The second was to impart into and preserve in inexperienced workers, basic work habits and skills - a sort of "basic training" role. The major worker maintenance oriented programme since 1981 has been the Project Employment Programme (PEP), with a role thus conceived exclusively in expectation of (or at least hope of) fugure economic conditions when it would not be relevant - i.e. conditions of "full employment" consistent with traditional work structures and norms. This is illustrated in Figure 3.

PEP employment, putatively low-priority public sector work, was defined as exclusively a "fill in", only a "stop-gap" measure. It was at all times ideologically and administratively subordinated to the private sector. PEP was "designed to help those who cannot be placed in unsubsidised jobs or private sector training and work" (ibid.. p 22), whereas "subsidised job creation in the private sector has the greatest potential for creating permanent jobs and therefore has the top priority...." (ibid.). It was thus implied that PEP was economically sterile. Notwithstanding this ideological ambivalence, PEP was in 1981 "now the largest nonseasonal job-creation programme in New Zealand" (J\&P 1981) and has remained in this position ever since. However the low-priority work and temporary nature of the employment ensured that in practice the conceivable contributions of PEP and other schemes to long term public works and community development functions were severely circumscribed (Cooney \& O'Connor 1983, O'Connor \& Brown 1983; O'Connor \& Endres 1985).

\section{The "bridge to nowhere"}

The J\&P thesis was that unemployment, while a major phenomenon at this time, was only temporary in nature and would vanish within (at most) a few years as the growth strategy fuelled economic "recovery". But there is nothing in the models or analyses of economic systems which are supposes may have underpinned this thesis, which could offer any guarantee that for New Zealand in practice growth was going to be achieved. At best, if the models were well-chosen, they might have informed strategy choices which offered reasonable expectations of growth subject to international conditions, etc. There was also no guarantee that GDP growth would be correlated significantly with an increase of job opportunities of the magnitude needed to mop up the projected increase in the potential adult workforce. In practice, the lack of growth in job opportunties during 1980-83 meant that the special schemes were unable to perform their putative functions.

The strictly temporary character of the public sector work programmes often made the work and financial support they provided a traumatic stop-go affair. Yet for many individuals. the subsidised employment programmes offered the best prospect they had for maintaining financial solvency and supporting family, mortgage commitments, rents, living costs, etc. For these people, the on-off character of short-term PEP work, and of the Department of Labour's uneven commitment to providing it, seemed contradictory and alienating (e.g. MCC 1983, O'Connor \& Brown 1983). With the shortfall of "real" jobs, for many PEP workers the next step was back on the dole. As the "minimum standdown period" for eligibility of a registered unemployed person was progressively increased during 1982 and 1983 up to 26 weeks, the public sector schemes became, for many people, a "bridge to nowhere". The policymakers' "bridge" concept had, for many people, little plausibility to it as the numbers of unemployed and of persons on "subsidised jobs" increased monotonically during 1981 and 1982, in combination exceeding 100,000 in late 1982 and through 1983.

\section{Training programmes and the Hansen "Task Force"}

This disparity between the purpose which the temporary scheme structure purported to serve (function as a bridge), and the actual situation (long-term of recurrent unemployment), meant for the policymakers a renewed pressure regarding the lack of credibility of the current employment policies. Widespread public dissatisfaction thus forced a reconsideration in 1982 of the job creation programmes, especially those concerning youth unemployment.

In mid-1982 the National Government set up a task force on youth training with apparently wide ranging objectives, including (1) To define, for comparative purposes, the 
cost, effectiveness, advantages and limitations for young job seekers of the present job creation and work development programmes presently funded by the public sector; and (2) To examine alternative solutions to the current and potential unemployment situation for the youth population. The Task Force's July 1982 discussion document Training and Employment for Youth: Options for Action (henceforth TFDD 1982) made clear than its brief was to be in practice very restricted. The Foreword informed:

Clearly measures to assist young people to obtain training and employment must be seen as part of a more comprehensive strategy to generate growth and employment throughout the whole economy. However it is not the aim of this paper to deal with the longer term growth strategy which is directed at reviving our economy and restoring a condition of full employment.

The paper is not proposing to tackle such other connected issues as industry of redundancy or remuneration for young fully employed workers. Nor is it intended to deal with training needs beyond sub-apprenticeship level. (TFDD 1982, p 2, emphasis added)

The discussion document then concluded with a pre-emptive "guide" to the subsequent round of public "submission":

The key issues which arise from the paper are probably summed up below and could provide a guide for you in the preparation of your responses to the paper:

- How feasible will it be to offer a flexible range of work and training opportunities; initially, to all 16 year olds requiring them and ultimately, to 17 year olds?

- Given the major additional funds that this will involve, at a time when stringent curbs on government expenditure are needed, how best might savings be made from other programmes?

- Are the measures proposed by the Task Force to encourage greater effort at the local level towards the creation of new work opportunities, sufficient to achieve this end or would other approaches be more effective?

- What would the most effective measures be to engage the maximum participation of people at community level? (ibid., p 17)

A fair rendering of the first sentence might have been, "which will guide you as to the terms within which we are prepared to consider your response". This restrictive approach was entirely contrary to the tenor of the majority of submissions subsequently made to the Task Force. What is important here is that the Task Force, and not those putatively making submissions to it, was inscribed (on its own authority) with the role of defining the appropriate parameters of policy debate regarding youth employment. In the eventuality the Task Force proposed a degree of reshuffling of restricted resources in the training/relief employment field with emphasis on school-leavers. The "package" of new programmes and modifications announced by the Government shortly before Christmas 1982 introduced a "new programme" to service 15 and 16 year old school leavers: STEPS, the School-leavers Training and Employment Preparation Scheme. Apart from this it largely curtailed the scope of existing programmes, reinforced the pre-trade skills "training" concept as a putative solution to unemployment difficulties, ignored or mis-represented many of the suggestions made to it, and (by its own admission) failed to grapple in a serious way with the implications of highlevel unemployment over the longer term.

The concept of PEP as a bridge, transparently inoperative, was abolished in favour of a revised function which made official its role as a place of socio-economic limbo. Henceforth:

The basic purpose of PEP is to assist in minimising long-duration unemployment. Therefore, it is to be targetted on those who, because of their duration of enrolment, are either long-term unemployed or at a clear risk of becoming long-term unemployed. Priority is to be given to longer-term enrolees. In effect, the programme is to become a last resort safety net..... (DOL Head Office Restricted Circular 188, 10 December 1982, p 7)

During the ensuing 18 months, the 8 week minimum stand-down period was increased to 13 weeks, and then to 26 weeks duration, in effect reducing PEP to a mechanism for rationing temporary work amongst the pool of unemployed. As regards WSDP, the press release accompanying the December 1982 changes insisted that "it has become necessary to reinforce the training emphasis of WSDP". The revised objective and target group of the programme were proclaimed as:

Objective: 'To assist towards unsubsidised employment those job seekers with identified barriers to getting a job which can be overcome through appropriate combinations of supervised training and work experience.

Target Group: The programme is intended specifically to assist unemployed job seekers for whom full-time training under the Young Persons Training Programme is inappropriate or 
who need a period of consolidating work experience and training following full-time training. (Press Statement, ibid.)

The restricted circular (op. cit. pp 4-5) specified that "job seekers must have identified barriers to employment ..... of a sort that can be overcome by a programme which combines supervised training and work experience ......"This "fresh emphasis on the training function of WSDP" ought to have excluded most unemployed young people from eligibility, as the new policy did nothing to overcome the main barrier to employment experienced by the potential "trainees" - the lack of job opportunities. Similar difficulties confronted the new STEPS programme, whose practical operation thus remained controversial. There have been some conspicuously successful projects, and some school-leavers have no doubt got valuable and enjoyable training experiences. Nonetheless, STEPS has suffered a severe external limitation to effectiveness: the lack of jobs to which the school leaver "trainees" can move. Counselling and basic training could not magicaly produce jobs, any more than with WSDP. In many people's views, the concept of the STEPS and WSDP schemes was inappropriate, not because they failed to generate permanent jobs (which was never expected of them), but because their putative functions were predicated on unrealistic and/or erroneous hopes or expectations of rapid growth in employment opportunities along traditional forms.

\section{The coercive nature of the special employment programmes}

A feature of the Government policy statements on employment throughout the 1980-85 period has been the insistence that all sectors of society must "work together" to solve the problem. In J\&P (1981, p 24) the rhetorical question was asked, "how can the Government, the employers, the unions and other organisations work together in reducing New Zealand's employment problems?" Who authorises the terms of the proper "participation"? It is clear that the National Government during 1978-84 ascribed itself the responsibility for defining the overall economic and employment strategy, and for informing the rest of "the community" of its roles in use of the instituted schemes.

The authorised version since 1980 had been that the nation (and unemployed people in particular) must wait for economic growth in order to have a return to full employment, must meantime go through phases of economic restructuring and adjustment, and that the spells of temporary "special work" and/or training scheme placements were all that was available to meet the interests of those bearing the brunt of economic recession. This represented a particular view of the world which not only informed the judgements of policymakers, but was progressively instituted as the "economic reality" in which New Zealanders (employed and unemployed alike) were required to "participate".

Local government and community organisations were in effect co-opted within this authoritative framework, to act as employing and administrative agencies executing the schemes as regulated through the Department of Labour. This co-option lent legitimacy to the policy regime, although continuing to deny to these bodies any significant influence over the basic forms the employment assistance structures could take. The appearance of large-scale "participation" by many individuals and organisations making up the community masked widespread frustration amongst many client and user groups with the short-term character of the schemes, the frequently arbitrary way in which the employment schemes were administered by the Department of Labour, the ways the programme placements were manipulated and constrained to disguise the long-term nature of the unemployment problem and stay within Departmental budget constraints, and the authoritarian lack of negotiability of how and for what purposes the schemes could be used. In practice many users of PEP, WSDP, VOTP and STEPS inverted the official transitionary character of the programmes, and used them towards ongoing personal, local economic, cultural, and community development activities in defiance of the stipulated conditions. But such autonomous 
exploitation of the schemes necessarily remained "off the record" and at risk of exposure with consequent punative withdrawal of access to the labour power resources which the schemes represented. $^{2}$

Though lip service was paid to the maintenance of consultation channels between policymakers and their client public during and after 1982, there remained an overt monopoly of power at the top. To say this is neither trivial, nor a tautological acknowledgement of the proper role of government. All of WSDP, STEPS, PEP, and VOTP have functioned as tools of legitimation for an ideology of economic development centred on the concepts of aggregate GNP growth, market efficiency (notwithstanding the so-called regulatory excesses associated with the Muldoon regime), and productive skills measured in dollar terms. A major ideological function of PEP, WSDP, and STEPS was to preserve the appearance of unemployed people as productive potentiality by reference to a vision of (sometime) future full participation in the workforce, where this potential could be realised.

In this respect, one function of the employment programmes was to shore up the psychological investment of the policymakers and dominant interest groups in the social roles, values, and objectives embodied in a growth-oriented economic system. Many, but not all, New Zealanders shared this investment. The policies put into place therefore gave recognition to the interests of unemployed individuals and other interest groups only to the extent that these people conceived of their own interests in terms consistent with this ideology of latent productive potential within a money economy.

Consistent with the desire to shore up this underlying ideological investment, prospective employers in the community (and in the private sector) were denied the right to utilise centrally administered resources through the employment programmes for purposes at odds with the specified objectives and guidelines of the schemes. This in practice amounted to a refusal to sanction or support the articulation of and implementation of responses consistent with groups and individuals own experiences of the social and economic problems of employment, to the extent that these experiences and motivations were incompatible with the ideology underlying the schemes. For example, in contradiction to the tenor of many community submissions to the Task Force, the STEPS programme was oriented exclusively in relation to preparation of young people for the work force in the sense of the money economy. STEPS was not to provide educational, cultural, or employment activities justified outside of this objective of providing a stepping stone towards the future of full (paid) employment participation. Rather than seeking to facilitate authentic grass-roots initiatives and responsibility, the policymakers in 1982 re-asserted unambiguously that tight centralised control was to be maintained over all employment expenditures. This authoritative control, often affirmed in terms of the need to ensure accountability for expenditure of public moneys, furthermore entirely obscured the essential desire for a degree of autonomy:

While it is recognised that there has to be nationwide consistency in the basic principles and objectives of the programmes, there was an underlying concern to see a more positive and flexible approach to programme principles and objectives. (DOL Circular No HO $51 / 180 / 1,10$ Dec 1982)

The Head Office spokesman did not specify who recognised the "need" for nationwide consistency. Certainly government insisted on it; many organisations and individuals had directly challenged it. The Head Office circular mystified this reality of fundamental debate about appropriate objectives and principles, and about where and in what terms account-

2. The stringency of imposition of the programme criteria however varied widely from one employment district to another. For example the Auckland metropolitan districts exercised a bureaucratically heavy hand (Cooney and O'Connor 1983: O'Connor and Brown 1983: MCC 1983, 1984). whereas greater "flexibility" was tacitly permitted in some rural areas (e.g. Bell 1983). The frustrations and controversies associated with the implementation and operations of the PEP. WSDP. and related programmes. and the various bureaucratic procedures within the Departments of Social Welfare and Labour in particular. have been documented widely. Large numbers of submissions to the Task Force on Youth Training and later to the 1985 Employment Promotion Conference included criticisms of the existing schemes, often for widely varying reasons. The nearest to comprehensive review studies known to the author include, in addition to those cited above, Gray and Neale (1984), several reviews undertaken by the Department of Labour (published in EP( 1985b): Dwyer and Willmott (1984). Views of unemployed groups and individuals are recorded in various issues of Doledrums, the newspaper put out by the Wellington Unemployed Workers Union (WUWU), and in the Employment Network newsletters. 
ability for employment initiatives should rest. The revised administrative structure was intended to "isolate and express clearly the basic princples of each programme and to specify the appropriate target group" and thereafter "to ensure that applicants are given positive assistance to help them satisfy those principles." In regard to this fourth requirement, it was added:

This is not an invitation to set aside the basic principles of any programme to meet an applicant's needs. Rather it is a requirement to offer positive guidance and help to applicants to formulate suitable applications so that they fit within the basic principles. (ibid.. p 2, emphases added)

In effect the policy sought to institute an administrative process which would impose an authoritatively conceived representation of how the employment problem was to be viewed, and what responses to it were legitimate. The Department of Labour officers were in effect instructed to give recognition to the efforts and concerns of people only insofar as they could be made to fit within the pre-determined framework laid down by the Wellington-based policymaking organs. The notion of each playing a role as espoused in Jobs \& People and elsewhere, was a mask for this process of authoritative inscription.

\section{Deja vu: the review of employment subsidy programmes}

It would be illegitimate to consign observations as to the coercive nature of policy documents to some era in the past. Central government institutions have continued under the current Labour administration to play pre-emptive authorising roles in employment policy, notwithstanding the aura of consensus and consultation which the new Government tried to foster.

In November 1984 a discussion paper Review of Employment Subsidy Programmes: A Framework for Consultation (henceforth RESP 1984) was published under the signature of Hon Kerry Burke, the new Minister of Labour. Its stated intention was to inform consultations leading up to the Employment Promotion Conference to be held in March 1985. This document presented a conceptual framework within which the consultations should, in the authors' view, appropriately take place. The RESP paper took as its underlying premises: (a) that the desired development path and adjustment of the New Zealand economic system is most efficiently achieved by broadly relying on market forces; (b) that it is the Government's role only to establish an environment within which renewed and sustained growth can occur (ibid.. p 5); (c) that given adequate growth we can expect employment to grow (ibid.); (d) that employment subsidy programmes (henceforth ESP's) can have no substantial role in the achievement of a healthy economy, and if they are justified at all it is only in an equity or welfare context, and quite separate from the wider aspects of an employment strategy concerned with overall growth in jobs.

An $a$ priori faith in the market institution seems to permeate the arguments in the document. Most economists, irrespective of their favoured choices of model or paradigm, will admit that there is no theoretic reason to believe that market forces will necessarily lead to a socially acceptable distribution of incomes and public costs/benefits in New Zealand. Further, where investments result in structural changes, in the opening up of new opportunities to different groups of economic agents, or change in any other way to the distribution of marketable endowments amongst members of our society, the efficiency criteria such as are central to the normative claims of neoclassical and the new classical economics are indeterminate as regards employment and other distributional effects. Resource reallocations resulting in structural or property rights changes may decrease the supply of jobs (as some of Think Big projects may have done, at least relative to other options), or they may increase and also change the distribution and types of jobs, e.g. altering patterns of relative privilege. Such changes are in fact very important in the context of New Zealand employment policy, for example in the debates about Maori economic development. autonomy at local and regional levels, women in the workforce, skilled and non-skilled jobs and so on. The repeated contention in RESP that "employment programmes do not increase the total number of jobs in the economy", and the relative neglect of issues of structural change and differential (dis)advantaging of different cultural values, therefore seem to have more of an ideological character than any rigorous empirical or theoretical basis.

Reboul (1980) defines ideology as a mode of thought which is partisan: the partial and polemical expression of a small group of people; collective: it is not specific to any particular 
individual within the partisan group; dissimulating: it does not define itself as partisan but on the contrary as rational; and it functions to the service of a power system in the society. The RESP's dissimulating character is most blatantly exhibited in its sections referring to the "needs of the unemployed".

The RESP framework, having ruled out the notion that ESP's could contribute to authentic job creation, in effect asserted the impossibility of ESP's to meet what most unemployed people define as their prime need (i.e. for secure employment). This impotence may well be true, although the RESP analysis is hardly conclusive. The more revealing feature is the RESP author's attempt to institute some new "needs" to whose satisfaction ESP's can within their model, plausibly be redirected. The reader was informed (ibid.. p 19) that while "employment programmes cannot create significant extra employment.... they can be used to help those among the unemployed who have the most difficulty finding work". The assistance envisaged was "programmes which can interrupt or prevent long or repeated spells of unemployment" ( $\mathrm{p} 10)$, and programmes to provide training to impart, extend or maintain work skills in the absence of "ordinary employment" (pp 10-11).

How plausible is it to argue that such a function is really meeting the real needs of unemployed people as these people themselves experience them? The RESP noted that "some groups in our society are having greater employment difficulties than others" (p 10), mentioning Maori and Pacific Islanders, women, some classes of young people, people falling in 2 or more of these groups; and also "those who have experienced repeated spells of unemployment". Given that some of the reasons for such patterns of disadvantage include mono-cultural, racist, sexist, and patriarchal attitudes still prevailing in many facets of our society and institutions, it is unlikely that ESP's which simply addressed a symptom (employment difficulties) could be of more than limited value to such groups. The RESP authors however had ignored any consideration of underlying structural, cultural, and attitudinal determinants of employment disadvantage, and largely neglected to examine the possible roles of ESP's or similar in effecting changes in investment, resource utilisation, and employment distributions aimed at redressing these patterns of relative disadvantage.

The implicit authority of Treasury or textbook economic theory of course hardly proves the validity of the perspective offered in the RESP. The fact is that many people in New Zealand do not identify their own employment needs and priorities in terms compatible with the framework presented in the RESP, and others would dispute on various analytic and ideological grounds the plausibility of that document's faith in "the market". This does not mean that people have got wrong ideas about economics, efficiency, development, distributional justice or anything like that. Rather, it stems from the fact that New Zealand people have amongst them got quite diverse understandings of what economic development, social change, relationships, labour and work might entail. The RESP paper seemed by contrast to have a very one-dimensional perspective on employment, namely that people either "have work" or are unemployed, are "participating" in the paid workforce or are "having difficulty". It showed no conception of the viability of strategies to change the system which go outside the adjustments supposedly induced or inducible through market forces, but also showed little respect for the likelihood that many people would sincerely disagree with its prognosis.

\section{The wake of the Employment Promotion Conference}

Participants at the March 1985 Employment Promotion Conference had to face up to continuing insistence, by unemployed and Maori interest groups in particular, that existing ESPs or measures along the lines advocated in the RESP had achieved and could achieve relatively little to meet the "real needs" of unemployed and disadvantaged groups. Much emphasis was placed by these delegates on initiatives and accountability at a regional and local level, and the need for increased government support for long-term employment-related programmes. Such strong stances disturbed and alienated some of the more traditionally oriented sector groups, especially employer representatives. It become obvious to all participants that the deep differences of views and priorities among the various interest groups could not be easily reconciled. The Minister of Employment in the official Conference Report (EPC 1985c) was explicit in admitting the absence of consensus and the political tensions inherent in choosing between "differing and sometimes conflicting interests of people involved in employment". In his concluding address to the Conference delegates, he acknowledged that many views expressed implied, if realised, a re-definition of traditional 
norms and values of work and employment:

The calls heard at this conference will also require reappraisal by the sector groups represented here of long-held views and attitudes, to assess whether they are in line with the mood of New Zealanders as we move towards the 1990s.

They will also require acceptance by the community at large of a change in the way it regards work. employment and enterprise...... A general acceptance by all New Zealanders of a wider and more flexible definition of work. employment and enterprise would be of particular value to women, cultural minorities, people disadvantaged by disablement and other groups who have felt most alienated by traditional definitions of work. (EPC 1985c. pp 63-64)

Mr Burke went on to acknowledge widespread calls for decentralisation of resources and decisionmaking to regional and local levels, and for special attention to needs of Maori people whose disadvantage "goes back many years further than the unemployment that the rest of us have experienced for the last ten years" (ibid.). This is a very different discourse from that of the J\&P TFDD and RESP documents. An inescapable tension exists between such movement as was authorised here into new structures and norms of employment, and the traditional work structures represented by employer and union representatives. Such changes would challenge traditional social values still dominant in the mainstreams of our society, and could also be perceived as threatening the viability of economic enterprise in traditional moulds.

The Labour Government therefore faced a further critical point concerning future strategy in the employment field: whether to retain the emphasis on "more market" which seemed their pattern in most other fields of economic policy, or to provide ideological and material support encouraging (some) New Zealanders to embark on paths piloting new directions of social/economic development, and accept the tensions between different cultural and economic visions. One would be at a loss as to how to represent such new directions on a single scale, but Figure 4 attempts to depict this.

Figure 4: Contradictory views of possible future work and employment directions, New Zealand $1982-1986$

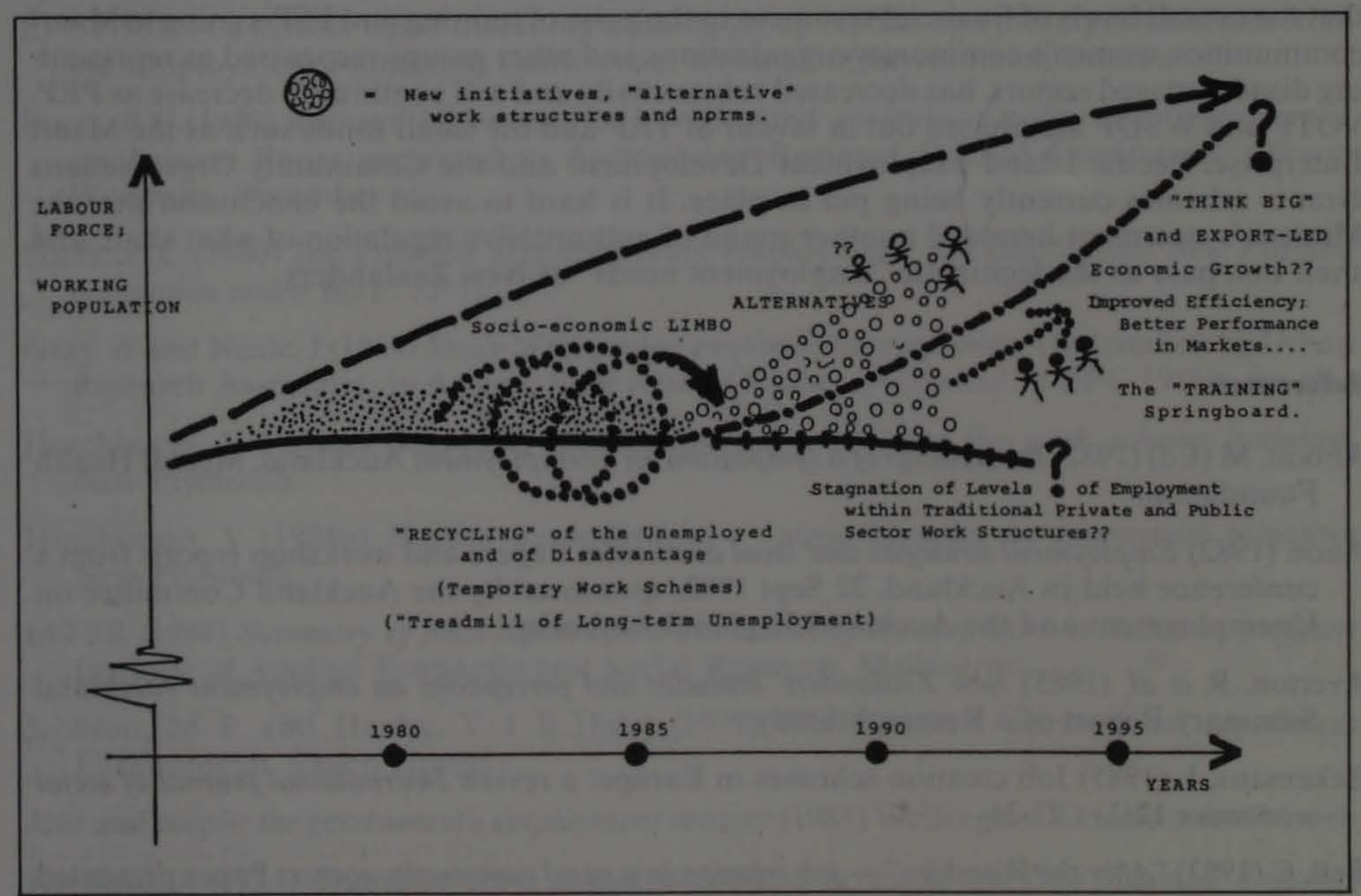

In June 1985 the Minister of Employment announced some "major new directions for employment and training assistance programmes". These were intended as "a major shift away from the essentially welfare based approach of the present schemes ..... to a more positive, developmental approach centred on systematic training." (Press Release). The new 
measures announced included 3 components: (1) the Job Opportunity Scheme (JOS) providing a partial wage subsidy to employers in any sector (public or private) who take on additional unemployed persons, and including a "Self Employment Option" which makes the wage subsidy payable to the individual directly with a "serious self-employment proposal"; (2) special assistance measures for Maori and Pacific Island communities, to the tune of a few millions of dollars allocated "for the communities themselves to spend on promoting viable, unsubsidised employment"; (3) A "new structure of transition education and training assistance designed to improve people's long-term earnings potential", the ACCESS concept (see SYP 1985). The training emphasis has since been augmented with the new Training Assistance Programme (TAP), currently (1986) being phased in.

In his June 1985 press release the Minister of Employment stated that "when all the changes are fully implemented, there would be a set of schemes which would meet the various employment needs of New Zealanders". This seems an excessive, and dissimulating, claim. As of early 1986, announced changes have gone only a very small distance to assist the needs of unemployed people as these were expressed at the EPC itself and as identified in independent sources (such as Averton et al. 1985; Hutchinson 1984a, 1984b). No overall increase in funding of ESP's was anticipated by government. In fact a decrease in the aggregate expenditure on ESP's seems likely. The financing of JOS and the other initiatives in 1985 came from the Vote: Labour allocations already provided for the fully subsidised schemes. Since mid-1985 the pressure on the unemployed generally and on disadvantaged groups in particular has been increased as a result of the phasing out of existing public sector employment programmes (as noted by Reid \& Swain 1985; Employment Network 1985, 1986).

\section{Conclusion}

Some of the recent policy changes do point in the sorts of directions advocated by disadvantaged interest groups at the EPC. But at the present time the committed resources involved in the pilots and assistance specifically to disadvantaged groups remains only of the order of a few percent of the level of 1984/85 employment subsidy measures. It seems likely that the overall levels of financial resources in the guise of training and ESP's going to Maori communities, women's community organisations and other groups recognised as representing disadvantaged sectors, has decreased substantially and will continue to decrease as PEP, VOTP and WSDP are phased out in favour of TAP and the small funds such as the Maori Enterprise, Pacific Island Employment Development and the Community Organisations Grants schemes currently being put in place. It is hard to avoid the conclusion that the Minister's statement heralded another round of authoritative regulation of what shall, and shall not, pass as the legitimate "employment needs" of New Zealanders.

\section{References}

Abbott, M (Ed) (1982) Proceedings of a symposium on unemployment Auckland, Mental Health Foundation.

Anon (1982) Employment strategies and local authorities Papers and workshop reports from a conference held in Auckland, 22 Sept 1982, sponsored by the Auckland Committee on Unemployment and the Auckland Regional Authority.

Averton, R et al. (1985) New Zealanders' attitudes and perceptions on employment Auckland Summary Report of a Research Study.

Bekemans, L (1985) Job creation schemes in Europe: a review International journal of social economics 12(1) : 27-36.

Bell, C (1983) "After the Wombles" - job creation in a rural community context Paper presented to New Zealand Sociological Association May 1983 Conference, University of Auckland.

Cooney. V and O'Connor. M P (1983) All that glitters, was it false gold: Auckland communities experiences with VOJCP Auckland, Auckland City Council Employment Department.

Cronin, K (1983) Unemployment and the emerging post-industrial economy: a feminist perspective Paper presented to the New Zealand Women's Studies Association Conference, Christchurch. 
Department of Labour Annual report Appendices to the Journal of the House of Representatives, various years.

Duff, B (1984) Employment. life and survival Matrix No 5. Hamilton

Dwyer, T and Willmott, W E (1984) Analysing PEP policy in Christchurch: lessons for sociologists Christchurch. Department of Sociology, University of Canterbury.

Dwyer, T (1981a) Job creation and social injustice National business review $16: 26$.

Dwyer, T (1981b) Cows, human beings and mobilisation: solving unemployment the fairest way possible National business review $16: 26-27$.

Dwyer. T (1982) Student work scheme scrapped - first steps to social conflict and coalition of unemployed groups? National business review $17: 26-27$.

Dwyer. T (1983) The fight against rising unemployment: gifts. . . and broken machines National business review $18: 7$.

Dwyer. T (1984) It went that-a-way?: the state's recent response to unemployment. In Wilkes C and Shirley I (Eds) In the public interest: health. work, and housing in New Zealand society Auckland. Ross.

Employment Network (1984-1986) Newsletter, various issues, published by the New Zealand Employment Network, Wellington.

Endres. T (1984) The New Zealand full employment goal. A survey of changing views, 19501980 New Zealand journal of industrial relations 9(1) : 33-34.

EPC (1985a) Submissions on employment, a conference discussion paper prepared for the Employment Promotion Conference. Wellington, Government Printer.

EPC (1985b) Studies of employment and training programmes published in conjunction with the Employment Promotion Conference, Wellington, Government Printer.

EPC (1985c) Conference report including working group reports and principal addresses from the Employment Promotion Conference. Wellington, Government Printer.

Forer, P C (1979) Regional job creation in New Zealand: government policy and "uneconomic" employment Paper presented to Australasian Regional Science Conference. AlburyWodonga. December.

Forer. P C (1980) Job creation and temporary employment: the last 5 years New Zealand population review $6(3): 33-37$.

Gray. A and Neale, J (1984) Study of the project employment programme Undertaken by Urban Research Associates, in 4 parts, final report October, published in EPC 1985b, op. cit.

Hutchinson, V (1984a) Organising the unemployed: evaluating the work scheme initiatives New Plymouth.

Hutchinson. V (1984b) Healing unemployment - some keynotes for community initiatives New Plymouth.

IAESR (1984) Summary of final report of the evaluation of the employment initiatives program Institute of Applied Economic and Social Research. Melbourne.

Jackson. M P and Hanby, V J B (Eds) (1979) Work creation, international experiences Farnborough, Saxon House.

Jobs and people: the government's employment stratgey (1981) Wellington. Government Printer.

Kerslake, J (1984) Transition from school to work: a review of the New Zealand literature Wellington. Department of Education Research and Statistics Division. Research Report Series No 35 .

Labour and employment gazette Wellington. New Zealand, various issues 1975-1985.

MCC (1983) Report on employment - job creation - social issues Appendix to Manukau City Council meeting. Auckland. 
MCC (1984) Manukau City employment policy paper Attachment to Manukay City Council Community Development Committee meeting. Auckland.

Mills, M (1985) Job creation and unemployment: a review and bibliography, prepared for the Auckland District Employment and Advisory Committee (DETAC), Auckland.

O'Connor, M P and Brown, S (1983) Bridge to nowhere: perceptions of temporary project employment Auckland City Council Employment Department.

O'Connor, M P (1983) Look a gift horse in the mouth: perspectives on the public sector job creation programmes Auckland City Council Employment Department.

O'Connor, M P et al. (1983) Once bitten, twice shy: fallacies of work skills development and STEPS Auckland City Council Employment Department.

O'Connor, M P and Endres, A M (1985) On the 'Review of Employment Subsidy Programmes' Policy Discussion Paper No 1, April, Department of Economics, University of Auckland.

Reboul, O (1980) Language et ideologie Paris, PUF.

Reid, $\mathrm{R}$ and Swain, $\mathrm{P}$ (1985) Towards an alternative employment strategy: regional planning and control of employment initiatives Paper for the International Employment Conference. Auckland.

RESP (1984) Review of employment subsidy programmes: a framework for consultation Government Printer, Wellington.

Rodin, S (1983) The preoccupation with occupation In Matrix No 3. Hamilton.

Shipley, S M (1982) Women's employment and unemployment Department of Sociology, Massey University.

SYP (1985) Skills for young people, a discussion paper on transition education and training Ministers of Education. Employment and Maori Affairs. Wellington, Government Printer.

TFDD (1982) Training and employment for youth - options for action: a discussion document Task Force on Youth Training, Wellington.

Wood. R (1982) Evaluation of public sector employment programmes in Anon (1982) Employment strategies and local authorities, op. cit

WUWU (1982) Dole-drums Newspaper of the Wellington Unemployed Workers' Union Wellington, various issues. 